\title{
Emergency hospital admissions for respiratory disorders attributable to summer time ozone episodes in Great Britain*
}

\author{
John R Stedman, H Ross Anderson, Richard W Atkinson, Robert L Maynard
}

\begin{abstract}
Background - There is accumulating evidence from various countries, including the UK, that ground level ozone concentrations are associated with increased daily hospital admissions for respiratory diseases. This paper estimates the impact of ozone episodes on daily hospital admissions for respiratory disease in Great Britain by combining locally based exposure-response relationships with mapped estimates of ozone exposure for the population in the summers of 1993 and 1995.

Methods - For the given years the available ozone measurements were used to construct maps of ozone concentrations for each day. The population exposed to a given concentration of ozone on a particular day was calculated from census data using a geographical information system. The additional hospital admissions for respiratory disease were then estimated using a regression coefficient for London.

Results - It is estimated that $0.10 \%$ (a total of 184) and $0.35 \%$ (a total of 643) of hospital admissions for respiratory disorders during the summers of 1993 and 1995, respectively, can be attributed to levels of ozone above $50 \mathrm{ppb}$ (the recommended air quality standard for the UK). A sensitivity analysis for 1995 found that, if no threshold is assumed, the estimate is increased by about twenty fold (6\% of admissions attributable).

Conclusions - The additional hospital admissions for respiratory disease attributable to ozone are very small in both absolute and relative terms if a threshold of $50 \mathrm{ppb}$ is assumed, but this estimate is very sensitive to threshold assumptions. (Thorax 1997;52:958-963)
\end{abstract}

Keywords: air pollution, ozone, respiratory admissions, air pollution mapping, risk assessment, health impact. Skipton House, 80 London Road, London SE1 6LW, UK

R L Maynard

Correspondence to: Dr J R Stedman.

* This article is published with kind permission of AEA Technology plc, Abingdon, Oxon, UK.

Received 13 March 1997

Returned to authors

8 June 1997

Revised version received

18 July 1997

Accepted for publication

4 August 1997

Ozone is a powerful oxidant and one of the most irritant of the common ambient air pollutants. It is produced during summer time "photochemical" smog episodes by the interaction of oxides of nitrogen and volatile organic compounds in the presence of sunlight. Ozone episodes are of concern due to the possible detrimental effects of periods of elevated ozone concentrations on human health, natural vegetation health, crop yields, and materials. ${ }^{1}$ Oxides of nitrogen are emitted mainly from the combustion of fossil fuels; about half of the total UK emissions are from road transport and about a quarter are from the electricity supply industry. ${ }^{2}$ About half of the total UK emissions of volatile organic compounds come from industrial processes and solvent use and about $40 \%$ come from road transport. Similarly, about half the total oxides of nitrogen emitted from European Union countries are from road transport, as are about a third of the emissions of volatile organic compounds. ${ }^{3}$ As ozone and its precursor emissions can be transported over large distances (several hundred $\mathrm{km}$ ), the assessment of adverse health effects of ozone episodes in the $\mathrm{UK}$ is also relevant to continental Europe.

Exposure chamber experiments show that ozone may cause local inflammation of the airways and lung at concentrations below those which may occur in ambient air in the UK. ${ }^{45}$ Recent epidemiological studies in North America and Europe, including the UK, have found small but significant associations between ozone and daily hospital admissions for respiratory disease. ${ }^{6-14}$ In order to inform policies for abatement, it is important to quantify in absolute and relative terms the contribution of ozone episodes to hospital admissions. The UK Expert Panel on Air Quality Standards (EPAQS) has recommended an ozone standard of $50 \mathrm{ppb}$ eight hour running average. ${ }^{15}$ We have defined an ozone episode as a concentration at or above this value. In this paper we report the development of a Geographical Information System based method for quantifying the health effects of ozone episodes and present estimates of the additional hospital admissions for respiratory disorders that can be attributed to photochemical ozone episodes in Great Britain (GB) during the summers of 1993 and 1995. The sensitivity of this estimate to various assumptions is also examined.

\section{Methods}

The method used comprised the following steps. Based on ozone concentrations obtained from UK monitoring networks, exposure of the whole population was modelled and $5 \times 5 \mathrm{~km}$ grid maps of the daily maximum eight hour average were calculated for each day of the summers of 1993 and 1995. Using a coefficient relating ozone to daily hospital admissions for respiratory diseases, the relative risk of ad- 
ditional admissions was estimated for each grid for each day on which ozone concentrations exceeded $50 \mathrm{ppb}$. The number of additional hospital admissions for each grid square for each day was then calculated from the relative risk for each square and a baseline estimate of the number of hospital admissions for respiratory disorders estimated from national census and hospital admission data. The additional admissions for each grid square in Great Britain were totalled for each day. The total additional admissions for each day were summed for all the days of the summer. The sensitivity of these estimates to the choice of exposure-response relationship and its precision, the choice of threshold, baseline hospital admission rate, and the procedure for mapping ozone concentrations were also examined.

EXPOSURE-RESPONSE RELATIONSHIP

The exposure-response relationship between ozone concentration and emergency hospital admissions for respiratory disease (IDC9 460519) for all ages of Ponce de Leon et $a l^{14}$ was used in this analysis. This regression coefficient was obtained from a study of eight hour average ozone concentrations (09.00-16.00 hours) and hospital admissions data for London for April to September 1987-91. The analysis followed the APHEA protocol. Briefly, this comprised Poisson regression of daily counts of hospital admissions for respiratory disease adjusting for the effects of time trends, seasonal and other cyclical factors, day of the week, holidays, influenza epidemics, temperature, humidity, and autocorrelation. It provided a coefficient which related the concentration of ozone to the natural logarithm of daily admissions. This may be converted to an estimate of relative risk of admissions for a given increment of ozone. ${ }^{16}$ There was little evidence that the effects of ozone observed are explained by covariation of ozone and other pollutants. ${ }^{14}$ The estimate obtained, which was used in this paper, was 0.00163 per ppb ozone (95\% CI 0.00083 to 0.00242 ) representing a relative risk of 1.04 (95\% CI 1.02 to 1.06 ) for a $25 \mathrm{ppb}$ increase in ozone concentration. This relative risk is very similar to that found in other European and American studies, which typically range from 1.02 to 1.05 for the same change in ozone concentration. ${ }^{17}$ Indeed, a meta-analysis of the results of an extension of the work of Ponce de Leon et al to a total of six areas in southern Britain (paper in preparation) also provided a relative risk very close to the value for London that we have used.

\section{THRESHOLD OZONE CONCENTRATIONS FOR} HEALTH IMPACT CALCULATION

The population comprises individuals who vary in their threshold for ozone effects, and in the actual dose of ozone received by the lung. For these reasons it is unlikely that a clear threshold of effect will exist at the population level. Furthermore, in the case of ozone, there is little difference between the community levels of exposure and the lowest level of effect dem- onstrable in chamber studies. ${ }^{4}$ Nevertheless, EPAQS have recommended an air quality standard for ozone for the UK of $50 \mathrm{ppb}$ as a running eight hour mean ${ }^{15}$ and WHO have recommended a health based air quality guideline for Europe of $60 \mathrm{ppb}$ for a running eight hour mean ozone concentration. ${ }^{18}$ EPAQS and WHO concluded that risks to health at such concentrations were unlikely and small, respectively. Neither the EPAQS nor the WHO recommendation should be taken as a demonstrated No Adverse Effect Level (NOAEL). For the purposes of this study it therefore seemed appropriate to adopt a threshold of $50 \mathrm{ppb}$ maximum eight hour average ozone concentration. The sensitivity to threshold assumptions is examined by using thresholds of $0,30,50$, and $60 \mathrm{ppb}$.

BASELINE HOSPITAL ADMISSIONS FOR RESPIRATORY DISORDERS

We used an estimate of 34.5 admissions for respiratory disease per 10000 population for the summer period. This was obtained from hospital episode system data for the six month period from April to September 1993 and represents the average value for England. The rate of admission per 10000 varied by Regional Health Authority from 26.4 to 46.4 . The number of admissions per 10000 per day was calculated by dividing the rate for the six month period by the number of days that this represents. This estimate $(0.189$ per 10000 per day) was used in the calculations of estimates of additional hospital admissions due to ozone episodes for both the summers of 1993 and 1995.

The total population potentially at risk in England in June 1993 was 48532700 and the total number of respiratory admissions for the summer of 1993 was 167340 . The total population of Great Britain represented by the $5 \times 5 \mathrm{~km}$ grid square map of population from the 1981 census used in this study was 53341200 . Assuming that the rate of respiratory admissions in Wales and Scotland is similar to the rate in England, the total number of respiratory admissions for the summer of 1993 for Great Britain is estimated at 183920.

\section{OZONE MONITORING DATA}

Ozone measurements were taken from the UK Department of the Environment Automatic Monitoring Networks. ${ }^{19}$ Hourly ozone concentration measurements for the summer of 1993 (April to September inclusive) were available from 15 sites within the Automatic Rural Monitoring Network (RMN) and 11 sites within the Automatic Urban Monitoring Network (AUN). Measurements for the summer of 1995 were available from $15 \mathrm{RMN}$ and 16 AUN sites. The RMN sites are generally in open country locations, in areas of low population density, well away from major roads and industrial areas. The majority of the AUN sites were in city centre locations and away from roadside locations. (Ozone concentrations at roadside locations are often significantly re- 
A

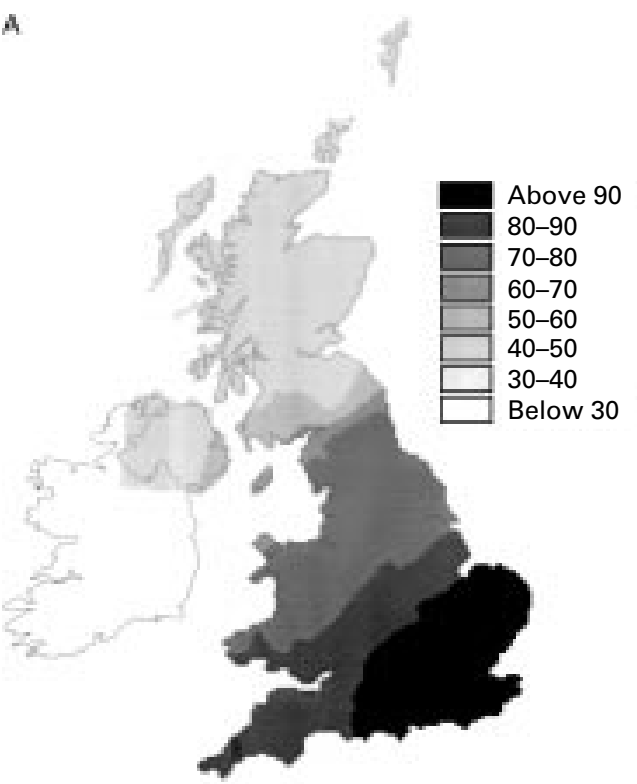

8

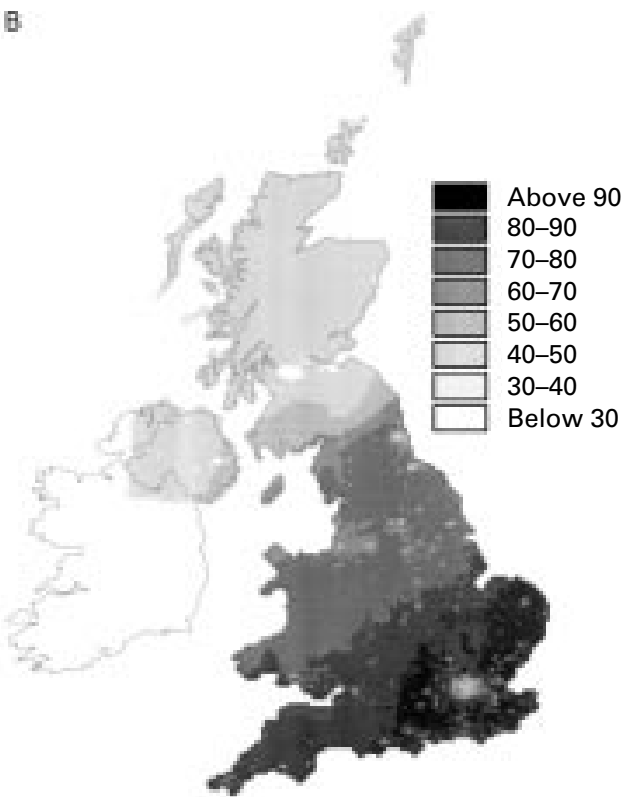

Figure 1 Maximum eight hour running mean ozone concentration (ppb) on 5 May 1995. (A) Map interpolated from measurements at rural sites; (B) map showing estimates for urban and rural areas (see text).

duced due to the close proximity to NO emissions from road traffic.)

The ozone monitoring sites with the highest number of episode days (with running eight hour mean ozone concentration greater than or equal to $50 \mathrm{ppb}$ ) per year are generally those in rural locations in the south of England. A smaller number of exceedances are normally recorded at more northerly sites or at sites in urban areas. Fifty three episode days were recorded at a rural site in south east England during 1995. This can be compared with a total of 10 for a site in central London, 22 at a rural site in northern Scotland, and only two at a site in central Edinburgh. ${ }^{19}$

Since ozone concentrations are only measured at a limited number of monitoring stations, concentrations at locations with no monitoring need to be estimated. While concentrations in rural areas can be interpolated directly from measurements, concentrations in urban areas can only be estimated by combining maps of rural ozone with a knowledge of the relationships between rural and urban concentrations and how these relationships vary with location and from day to day.

\section{MAPPING DAILY OZONE CONCENTRATIONS}

The maximum running eight hour average ozone concentration was calculated at each site for each day. A map of rural ozone concentrations was calculated by interpolation from measurements at rural sites (an example is shown in fig 1A). The daily maximum running eight hour average ozone concentration in urban areas tends to be different from the grid square value interpolated from rural measurements because the NO present in urban areas (a large proportion of which is emitted from vehicles) reacts with ozone to produce
$\mathrm{NO}_{2}$, reducing the ambient ozone concentration. ${ }^{1}$

Ozone measurements are available in a number of urban areas for the summers of 1993 and 1995. These can be compared with the interpolated rural ozone values and an urban influence, UI, can be defined as:

$\mathrm{UI}=(($ rural interpolated ozone $)-($ urban meas ured ozone))/(rural interpolated ozone)

The UI in urban areas will lie between 0 and 1. It is not possible to measure ozone concentrations in all $5 \times 5 \mathrm{~km}$ grid squares and hence to calculate the UI for each square directly from measurements. Values of UI for each day for each urban area in the country must therefore be estimated before a map of ozone concentrations can be calculated.

It is assumed that, for a constant NO emission intensity, UI will remain constant on a particular day across distances of several tens of $\mathrm{km}$, for which the meteorology should be consistent. If a linear relationship between UI and an indicator of $\mathrm{NO}$ emission intensity is assumed (for constant meteorology), then a strength of urban influence factor "a" can be calculated for each urban monitoring site for each day.

$$
\mathrm{UI}=\mathrm{a} \times \text { urblc }
$$

where "urblc" is the proportion of land cover that is defined as urban or suburban within a $5 \times 5 \mathrm{~km}$ Land Cover Map of Great Britain. ${ }^{20}$ Land cover information has been used in preference to published $\mathrm{NO}_{\mathrm{x}}$ emission inventories which are currently only available for the UK at a grid resolution of $10 \times 10 \mathrm{~km} .^{2}$

The strength of urban influence factor "a" will not necessarily be constant across the country on a particular day due to variations in meteorology over distances greater than several 
Table 1 Estimated number of additional hospital admissions for respiratory disorders that can be attributed to photochemical ozone episodes in Great Britain for the summers of 1993 and 1995

\begin{tabular}{|c|c|c|}
\hline & $\begin{array}{l}\text { Log admissions per } \\
p p b \quad \mathrm{O}_{3} \text { coefficient }\end{array}$ & $\begin{array}{l}\text { Estimated additional } \\
\text { hospital admissions }\end{array}$ \\
\hline Estimate for 1993 & 0.00163 & 184 \\
\hline Estimate for 1995 & 0.00163 & 643 \\
\hline 1995 lower $95 \%$ confidence limit & 0.00083 & 324 \\
\hline 1995 upper $95 \%$ confidence limit & 0.00242 & 964 \\
\hline 1995 coefficient derived from WHO ${ }^{18}$ & 0.00381 & 1545 \\
\hline
\end{tabular}

A threshold ozone concentration of $50 \mathrm{ppb}$ and an expected hospital admission rate of 35.4 per 10000 were assumed. Estimates derived using coefficient from Ponce de Leon et $^{2} \mathrm{l}^{14}$ are shown along with estimates for $95 \%$ CI and WHO coefficient for 1995 .

tens of $\mathrm{km}$. An interpolated map of "a" was therefore calculated for each day and combined with the land cover information to calculate a map of UI for each day. A map of daily maximum running eight hour average ozone concentration in urban and rural areas was then calculated from the rural ozone map and the map of UI (an example is shown in fig 1B):

Estimated ozone $=\mathrm{UI} \times$ rural interpolated ozone

\section{CALCULATION OF ADDITIONAL HOSPITAL}

ADMISSIONS

The relative risk of hospital admissions for respiratory disorders for each day and each grid square was calculated if the mapped ozone concentration was $\geq 50 \mathrm{ppb}$ :

relative risk $=\exp (($ ozone -50$) \times 0.00163)$

The percentage increase in hospital admissions (the additional risk) can therefore be calculated as $100 \times($ relative risk -1$)$. The number of additional hospital admissions for respiratory disorders due to ozone for each grid square for each day was then calculated from the relative risk for each square, population census data, and an estimate of the expected average number of hospital admissions for respiratory disorders for England for the summer months. The total number of additional admissions for each day attributable to ozone was then summed from the admissions in each individual grid square and these daily totals were summed to provide an estimate of the total number of additional admissions for the whole summer.

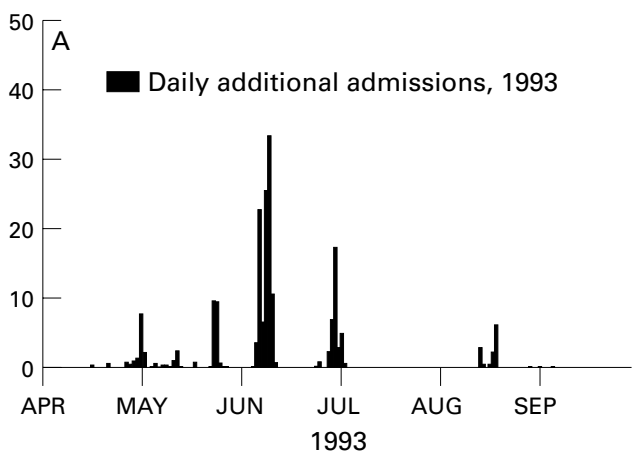

Results

It is estimated that the number of additional hospital admissions for respiratory disorders that can be attributed to photochemical ozone episodes in Great Britain for the summers of 1993 and 1995 are 184 and 643, respectively (table 1). These estimates represent $0.10 \%$ and $0.35 \%$ of the total admissions for respiratory disorders during the summers of 1993 and 1995.

Figure 2 shows the estimated number of daily additional hospital admissions for the two summers. This illustrates the greater impact of ozone episodes during 1995 and the relatively small number of episode days on which these additional hospital admissions are expected to have been caused. Most high ozone days occurred as part of a cluster of several high days. Estimates for these two summers provide an indication of the likely range of the impact of photochemical ozone episodes on hospital admissions from year to year because there were relatively few ozone episodes in the UK during 1993 and many more during $1995 .{ }^{19}$

The sensitivity of the estimates was investigated in relation to the choice and precision of the exposure-response estimates, threshold of effect, baseline hospital admission rate, and ozone mapping procedure.

The estimated total number of additional hospital admissions for respiratory disorders depends approximately linearly on the relative risk coefficient used. Table 1 shows that the estimates derived for the summer of 1995 from the $95 \%$ confidence limits of the combined coefficient used in this study range from 324 to 964 .

An estimate of additional hospital admissions for the summer of 1995 was also calculated using a relationship between this health outcome and changes in peak daily ozone concentration presented by $\mathrm{WHO}^{18}$ of a $10 \%$ increase in admissions for a $25 \mathrm{ppb}$ change in eight hour ozone concentration. This gave an estimate over twice as high as that obtained using the coefficient derived from studies in London.

The calculated number of additional hospital admissions is extremely sensitive to the value of the threshold ozone concentration used and this is the cause of one of the largest un-

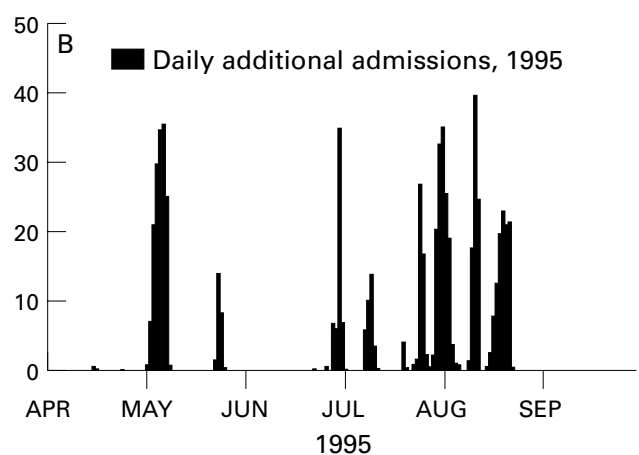


Table 2 Variation in the estimated number of additional hospital admissions for respiratory disorders that can be attributed to photochemical ozone episodes in Great Britain for the summer of 1995 according to threshold ozone concentration

\begin{tabular}{lc}
\hline $\begin{array}{l}\text { Threshold ozone concentration } \\
\text { (daily maximum running eight }\end{array}$ & $\begin{array}{l}\text { Estimated additional } \\
\text { hourpital admissions }\end{array}$ \\
\hline 0 & \\
30 & 11195 \\
50 & 2574 \\
60 & 643 \\
\hline
\end{tabular}

A coefficient of 0.00163 and an expected hospital admission rate of 35.4 per 10000 were assumed.

certainties in the estimates. The estimated number of admissions is halved by increasing the threshold from 50 to $60 \mathrm{ppb}$, which is the health based air quality guideline for Europe recommended by $\mathrm{WHO}^{18}$ (table 2). The daily maximum running eight hour average ozone concentration is frequently in the range of $0-50 \mathrm{ppb}$ during the summer months. The number of additional hospital admissions calculated with no threshold - that is, a threshold of $0 \mathrm{ppb}-$ is therefore much higher (see table 2 ), this figure representing more than $6 \%$ of total admissions for respiratory disorders.

The estimated total number of additional hospital admissions for respiratory disorders depends linearly on the expected rate of hospital admission for respiratory disorders used. The rate of admission per 10000 for English health authorities for the summer of 1993 varied from 26.4 for the lowest regional health authority to 46.4 for the highest, with an average value of 34.5. This is an estimate of the range of likely admission rates for any given area.

The estimates of the number of additional hospital admissions are sensitive to the mapping procedure and, in particular, to the way that the ozone concentrations in the urban areas are estimated. This estimation procedure is dependent on several assumptions concerning the relationship between urban ozone concentrations and those in the surrounding rural areas. An example of a map of interpolated rural ozone concentration and the same map with the correction for urban areas applied is shown in fig 1. It is reasonable to assume, however, that under UK conditions the ozone concentration within a city may be lower but will be no higher than that in the surrounding countryside. An estimate of the number of additional hospital admissions has therefore been calculated for the summer of 1995 using interpolated rural ozone concentrations for the whole of the country with no correction for urban areas. This gives a total of 1177 admissions for a relative risk coefficient of 0.00163 , a threshold of $50 \mathrm{ppb}$, and an expected rate of hospital admissions of 34.5 per 10000 . This is rather less than twice the estimate of 643 admissions obtained for urban corrected ozone maps. This estimate therefore provides an upper limit to the sensitivity of the admissions estimates to the treatment of urban ozone concentrations.

\section{Discussion}

This study has estimated, for the first time, the effects of ozone on daily hospital admissions for respiratory disease in the UK by combining locally based exposure-response relationships with modelled estimates of ozone exposure for the population of Great Britain.

We chose to concentrate on the effects of ozone above the EPAQS standard of $50 \mathrm{ppb}$ as a running eight hour mean because this would estimate the additional admissions associated with ozone episodes. Moreover, evidence from the London area has indicated a threshold at about this point. ${ }^{14}$ The size of effect was influenced by the ozone levels of the summers studied, the choice and precision of the regression coefficient, the assumed baseline admission rate for respiratory diseases, and assumptions about the urban influence on ozone concentrations. However, whatever these assumptions, the size of the effect was found to be quite small (less than $1 \%$ of admissions explained by ozone episodes).

The other approach explored was one which did not assume a threshold and estimated excess admissions across the whole range of ozone exposures. This led to estimates of effect which were of an order of magnitude greater than those obtained using the threshold approach. Individuals probably vary in their threshold level and are exposed to a wider range of pollutant concentrations than indicated by the community monitor. This argues against the threshold approach at the population level and was the rationale for the WHO decision to describe exposure-response relationships to ozone and other pollutants as a continuum. ${ }^{18}$ We believe that the most appropriate estimate is in the range between the threshold and no threshold estimates.

Another uncertainty concerns the possible effects of the clustering of the highest ozone days into a small number of episodes each of several days duration (fig 2). This might lead to an overestimation of additional admissions if the vulnerable population was reduced on the second or successive days of the episode. Alternatively, if the effects of ozone on the lung were cumulative, then the effects might be greater on subsequent days than on the first days of high exposure. Chamber studies have shown that the response of lung function to ozone falls after the second day of exposure. ${ }^{4}$ The mechanisms underlying this effect are not well known and there is a suspicion, based on experimental studies, that the inflammatory response of the airways is maintained despite the fall off in changes in indices of lung function. This response might reflect enhanced defence mechanisms or damage resulting in a failure to respond. ${ }^{4}$ We have therefore not attempted to take the effect of this clustering into account in our estimates of the number of additional hospital admissions.

The daily time series approach estimates the additional admissions attributable to an increment of ozone on a particular day. In itself, the analysis does not provide information about how these additional admissions arise. In particular, it is unclear whether these are ad- 
missions which would not have occurred without the increase in ozone exposure or inevitable admissions which were brought forward by the increase in ozone by a short period of a day or so. Uncertainty as to what proportion of admissions were actually additional makes it difficult to estimate additional costs to the Health Service.

The associations between ozone and hospital admissions were based on observational epidemiological evidence arising from complex statistical procedures and, while most authorities accept that these associations are not statistical artefacts, there remain questions about the causal nature of these associations and whether ozone itself is responsible or some closely related pollutant. Thus we cannot be sure whether a reduction in ozone would reduce admissions to the extent predicted by the model. A reduction in the emissions of air pollutants which contribute to ozone episodes would, however, be likely to reduce the concentrations of all pollutants associated with photochemical smog episodes.

Finally, it is important to appreciate that hospital admission is but one possible indicator of the health effects of ozone. There is also evidence that ozone is associated with an increase in daily mortality and with short term effects on respiratory symptoms and lung function. ${ }^{21-23}$ Given the widespread exposure of the population to ozone and the high incidence of acute respiratory symptoms, the health impact of ozone on respiratory morbidity may be much greater than suggested by an analysis restricted to hospital admissions alone.

The hospital admission time series analysis was funded by the National Asthma Campaign. The ozone mapping and estimation of hospital admissions work was funded by the Department of the Environment, contract numbers PECD 7/12/ 150 and EPG 1/3/75. Hospital admissions data were provided by the Lung and Asthma Information Agency. Valuable comments on early drafts of this work were received from Michal Krzyzanowski, Martin Williams, David Strachan and Geoff Dollard.

1 PORG. Ozone in the United Kingdom 1993. Third report of the Photochemical Oxidants Review Group. Department of the Environment, 1993.

2 Salway AG, Goodwin JWL, Eggleston HS. UK Emissions of Air Pollutants 1970-1993. National Atmospheric Emissions Inventory, AEA Technology, National Environmental Technology Centre 1996; Report AEA/ vironmental Technology

3 Corinair. Corinair 90: Summary Report no.1. Report to the European Environment Agency from the European Topic
Centre on Air Emissions. Copenhagen: EEA/053/95, 1995.

4 Department of Health Advisory Group on the Medical Aspects of Air Pollution Episodes. Ozone. London HMSO, 1991.

5 American Thoracic Society. Health effects of outdoor air pollution. Am F Respir Crit Care Med 1996;153:3-50.

6 Bates DV, Sizto R. Relationship between air pollutant levels and hospital admissions in Southern Ontario: the acid summer haze effect. Environ Res 1987;43:317-31.

7 Burnett RT, Dales RE, Raizenne ME, Krewski D, Summers PW, Roberts GR, et al. Effects of low ambient levels of ozone and sulfates on the frequency of respiratory admissions to Ontario Hospitals. Environ Res 1994;65: 172-94.

8 Delfino RJ, Becklake MR, Hanley JA. The relationship of urgent hospital admissions for respiratory illness to of urgent hospital admissions for respiratory illness to
photochemical air pollution levels in Montreal. Environ Res 1994;67:1-19.

9 Schouten JP, Vonk JM, Graaf AD. Short term effects of air pollution on emergency hospital admissions for respiratory pollution on emergency hospital admissions for respiratory disease: results of the APHEA project for two major cities Health 1996;50 (Suppl 1):S22-9.

10 Schwartz J. Short-term fluctuations in air pollution and hospital admissions of the elderly for respiratory disease. Thorax 1995;50:531-8.

11 Schwartz J. Air pollution and hospital admissions for respiratory disease. Epidemiology 1996;7:20-8.

12 Thurston GD, Ito K, Kinney PL, Lippmann M. A multi-yea study of air pollution and respiratory hospital admissions in three New York State metroplitan areas: results for 1988 and 1989 summers. $\mathcal{F}$ Exp Anal Environ Epidemiol 1992 2:429-50

13 Dab W, Medina S, Quenel P, Le Moullecy, Le Tertre A, Thelot B, et al. Short term resiratory effects of ambient air pollution: results of the APHEA project in Paris. $\mathcal{F}$ Epidemiol Community Health 1996;50(Suppl 1):S42-6.

14 Ponce de Leon A, Anderson HR, Bland JM, Strachan DP, Bower J. The effects of air pollution on daily hospita admissions for respiratory disease in London: 1987-88 to 1991-92. I Epidemiol Community Health 1996;50(Suppl 1):S63-70.

15 EPAOS (Department of the Environment Expert Panel on Air Quality Standards). Ozone. London: HMSO, 1994.

16 Schwartz J, Spix C, Touloumi G, Bacharora L Barnmamdzadeh T, Le Tertre A, et al. Methodological issues in studies of air pollution and daily counts of deaths or hospital admissions. 7 Epidemiol Community Health 1996;50(Suppl 1):S3-11.

17 Spix C, Anderson HR, Schwartz J, Vigotti M, Le Tertre A, Vonk J, et al. Short term effects of air pollution on hospital admissions of respiratory diseases in Europe A quantitative summary of APHEA study results. Arch Environ Health (in press).

18 World Health Organization. Update and revision of the air quality guidelines for Europe. Meeting of the Working Group "Classical" Air Pollutants, Bilthoven, The Netherlands, 11-14 October 1994. EUR/ICP/EHAZ 9405 PB01. WHO Regional Office for Europe, Copenhagen, 1995.

19 Bower JS, Broughton GFJ, Willis PG, Clark H. Air pollution in the UK: 1995. AEA Technology, National Environmental Technology Centre, 1997.

20 Fuller RM, Groom GB, Jones AR. An automated classification of Landsat Thematic mapper data. Photogrammetric Engineering and Remote Sensing 1994:60: 553-62.

21 Anderson HR, Ponce de Leon A, Bland JM, Bower J, tion and daily mortality in London: Strachan DP. Air pollution and daily mort 1997 . BMf 1996;312:665-99.

22 Delfino RJ, Coate BD, Zeigler S, et al. Daily asthma severity in relation to personal ozone exposure and outdoor fungal spores. Am 7 Respir Crit Care Med 1996;154:633-41.

spores. Am f Respir Crit Care Med 1996;154:633-41.
23 Kinney PL, Thuston GD, Raizenne M. The effects of ambient ozone on lung function in children: a reanalysis ambient ozone on lung function in children: a reanalysis 104:170-4. 